\title{
Dot-Gone: Fate Of A Dot-Com Enterprise
}

Doris Duncan, (E-mail: doris.duncan@csueastbay.edu), California State University, East Bay

\begin{abstract}
This case describes the start-up challenges confronted by an enterprising young entrepreneur in creating a home-based electronic commerce store. In contrast to all the get rich quick hype we have heard about, the value of this example lies in the fact that it identifies some of the real challenges--technical, management and marketing-- faced by new web-based ventures. It also gives a glimpse of some of the potential benefits and pitfalls of a web-based retailing enterprise. The beginnings of a start-up, creation and maintenance of a web-based business, and then the ultimate shutdown of the company are discussed.
\end{abstract}

\section{INTRODUCTION}

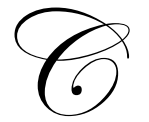

OMICSTAND.COM was an electronic commerce store (formerly http://comicstand.com) that specialized in selling comic books, action figure toys, and other comic related merchandise. The company sold all of its merchandise worldwide over the Internet; it had no physical storefront. Customers paid mostly by VISA or MasterCard, although personal checks were accepted. Products were packaged and sent to customers via UPS and the US Postal Service. The COMICSTAND.COM store site went on line and operated for about a year. The company and its web site were operated solely by the proprietor out of his home office.

The owner had a clear vision of the purpose of the web site and direction it was to take. He believed that his e-commerce model would specifically enable him to:

- $\quad$ sell specialty items -- comic books

- $\quad$ to establish a positive company image

- $\quad$ to add information value for current and future customers

- $\quad$ to contain the costs of operation (e.g., no physical store front or clerks)

- $\quad$ to develop new customers worldwide

- $\quad$ to research competitors and new products

- $\quad$ to participate in the business model of the "new economy" by gaining first hand experience.

Most comic book publishers begin delivering comic books to distributors and retail stores every Wednesday. Customers typically purchase comic books through convenience stores or specialized comic book bricks-and-mortar stores. Customers are typically, although not exclusively, young casual readers or serious adult collectors.

Since COMICSTAND.COM was focused on the comic book market, the products section of the web site got updated every Thursday in order to prepare for taking orders the following Wednesday. Comic book products stayed in inventory until the next issue was released or the item was sold out, whichever occurred first.

\section{WEB SITE CREATION AND MAINTENANCE}

A key question facing most companies, including COMICSTAND.COM, who are wanting to provide an electronic commerce site on the Internet is whether or not to develop and run their own sites in-house -- to host or not to host. It is relatively easy for anyone to develop a simple static Web page, but it remains an entirely different matter to develop an e-commerce site with order processing capabilities. The latter requires hard to find technically savvy personnel, specialized software often costing between $\$ 1,000$ - 5,000 or more, and fairly robust hardware and network 
connections. In general, the ideal choice for most small businesses is to contract with a third party to develop and host the web site. Costs for third-party hosting vary widely, for example, from $\$ 100$ per month for small stores selling up to 50 items on Yahoo!Store or Hypermart to $\$ 15,000$ and up for personalized design features along with monthly hosting connection charges and additional charges for each product or feature update.

In the case of COMICSTAND.COM, the owner was technically savvy, but possessed little working capital and did not want to borrow money to get started. From a practical standpoint, the owner was also doubtful that an e-commerce hosting company could even provide the necessary weekly updates and information content in a timely manner. Finally, he viewed the site as an opportunity to learn about e-commerce business models first hand. From the beginning, the owner figured that even if the site were to fail, it would afford him the opportunity to obtain great work experience that could be leveraged to get a job in the future. In short, the owner chose to develop and maintain the site himself. He already had a high-end computer but needed to purchase specialized e-commerce software for about $\$ 1,000$.

Some site features and business policies that the owner had to address included shopping cart features, payment methods, order confirmation, security features, shipping, and return policies. A shopping cart keeps track of what the customer has selected to purchase and allows the customer to view what is in the cart, add new items to it, or remove any items from it. To order an item, the customer simply clicks the items and all the details about it are stored automatically. When ready to pay for the purchases, the customer clicks a button (usually labeled proceed to checkout) and commits to the purchase transaction. Payment methods for credit card purchases need to be established and typically require establishing a bank merchant account. Security is usually built into e-commerce software and uses encryption methods to safeguard personal data. Frequently, the service of a third-party authentication service is also used to validate a site's security. When customers make purchases, it is necessary to build in a function that automatically confirms receipt of their orders (usually by sending the customer an e-mail with order number and other information on it). Finally, it is necessary to establish a merchandize return policy and shipping policies. These policy issues are business decisions more than they are technical decisions.

The owner confronted several limitations of the e-commerce package currently being used. For example, one of the initial challenges for COMICSTAND.COM was the procedure for updating its web site. The e-commerce software used by COMICSTAND.COM required that products be entered into its database manually. The program then generated HTML-based pages that linked to the program's shopping cart. Updating manually required filling out web-based forms, which was very time-consuming. The speed of processing web-based forms was also constrained by modem speed and the speed of the web server. If an item was no longer for sale, it had to be removed in a hurry from the database so that customers would not get frustrated by ordering out-of-stock items. Also, the software used did not automatically save the sales history of a given item.

The e-commerce package provided web based sales orders to be printed and downloaded as text. However, there was no internal system to produce either sales orders or purchase orders, and then automatically link these to accounting packages. Sales and purchase orders are important both for accounting purposes and as a basis for decision-making. The owner had planned to look for software in the future that would add these integrated functionalities, as well as others like maintaining mailing lists and financial reports generation. Advances in e-commerce software functionality and ease of use continue to occur rapidly, but are still not for the novice computer user.

In summary, the majority of the owner's time was clearly spent on just maintaining technical aspects of the site. The remainder of his time was spent on such tasks as actually shipping the orders, purchasing, inventory control, marketing, and bookkeeping. He had planned to hire other employees to help with order fulfillment, shipping, and returns processing, but never got to this point. 


\section{SHUT DOWN}

COMICSTAND.COM cost the owner the price of e-commerce software and countless hours of development time. Estimating conservatively, the owner spent a minimum of 20 hours per week over a three-month period just to get the site up and running. If he paid himself $\$ 25.00$ per hour, his initial development costs alone were $\$ 6,000(80$ hours per month $x 3$ months $x$ \$25.00). It was estimated that he probably spent another 10-15 hours per week to just maintain the site with weekly updates of products. Sales revenue did not justify continuing this investment so the proprietor shut it down. Although COMICSTAND.COM was a privately held company that was understandably reluctant to share sales data, the owner did indicate that monthly sales growth was increasing slowly. His main concern became the marketing issue of how to get more people to visit his site and actually purchase items. To use an analogy, he had "built the ballpark, but recognized that fans won't necessarily come!" Not many did, and COMICSTAND.COM became a DOT GONE. At last check, the domain name COMICSTAND.COM was for sale. The owner accepted an excellent position with Yahoo.

\section{NOTES}




\section{NOTES}

